\title{
Echocardiographic visualisation of the interatrial baffle after Mustard's operation
}

\author{
STEWART HUNTER, CARLOS MORTERA, GORDON TERRY, \\ ANTHONY GOODWIN, MICHAEL TYNAN, AND MICHAEL HOLDEN
}

From the Department of Cardiology, Newcastle General Hospital, Westgate Road, Newcastle upon Tyne

Thirty children aged from 7 weeks to 14 years were examined by echocardiography after Mustard's operation for transposition of the great arteries. Discrete and persistent echoes were noted within the original left atrial cavity and contrast echocardiography was used to establish that these originated from the interatrial baffle. In the presence of caval channel obstruction, caused by malposition or shrinkage of the baffle, significant differences were seen in the echocardiographic appearances of the baffle, namely limitation of baffle motion, thickening, and multiplicity of the baffle echoes. These findings suggest that the technique may be of value in the postoperative assessment of patients with transposition of the great arteries.

The principal complications of Mustard's operation (Mustard, 1964) for transposition of the great arteries, namely vena caval or pulmonary venous obstruction, are the result of malposition or shrinkage of the baffle (Stark et al., 1972).

Echocardiograms of patients after Mustard's operation have shown discrete and constant echoes within the original left atrial cavity. A previous report by Nanda et al. (1975) suggested that these echoes originated from the baffle. The purpose of the present study was to confirm that the baffle was the source of these echoes and to see if postoperative complications produced significant changes in their appearance.

\section{Patients and methods}

Thirty patients from 7 weeks to 14 years (mean age 4 years 9 months) were studied 2 weeks to 8 years after Mustard's operation for transposition of the great arteries. An echocardiographic examination was performed after operation in all 30 patients, 25 being studied in the outpatient clinic. All 30 also had right heart catheterisation and angiocardiography to assess the postoperative haemodynamic state. Single probe echocardiograms were recorded using a $2 \cdot 25 \mathrm{MHz}$ transducer focused to $7 \mathrm{~cm}$, a Picker Echoview X echocardiograph, and a Honeywell 1856 ultraviolet recorder. Events in the cardiac cycle were timed from a simultaneously recorded electrocardiogram. The probe was placed on the Received for publication 31 January 1977 chest wall in the third or fourth left intercostal space close to the sternal edge. Echocardiographic scans of the heart were carried out in the usual manner and all 4 valves, the great arteries, the ventricles, and the interventricular septum were visualised. The mitral valve was then relocated and the probe angled superiorly so that the beam transected the pulmonary artery and the original left atrium at a point where the pulmonary valve cusps could be seen; at this point a persistent echo was recorded in the original left atrial cavity.

Fig. 1 shows a necropsy specimen of a case of transposition of the great arteries after Mustard's operation. The heart has been cut sagittally to simulate the approximate plane of the echocardiographic beam as it passes through the pulmonary artery and original left atrium. The interatrial baffle, in this case of 'dacron', can be seen within the atrial cavity.

In 8 patients contrast echocardiography (Gramiak et al., 1969; Seward et al., 1975) was performed during postoperative right heart catheterisation. Echocardiograms were recorded during the injection of 2 to $5 \mathrm{ml} 5$ per cent dextrose (Valdes-Cruz et al., 1975) into the superior vena cava with the probe positioned to show the midatrial echo as described above.

\section{Results}

In all 30 patients a persistent and constant echo was seen in the centre of the original left atrial 
cavity (Fig. 2). In 26 cases this echo was single, well defined, and did not exceed $2 \mathrm{~mm}$ in thickness. In the remaining 5 cases more than one echo was present continuously and 4 of these had significant superior vena caval channel obstruction shown at cardiac catheterisation by the presence of peak pressure differences between the superior vena cava and the systemic venous atrium ranging between 7 and $30 \mathrm{mmHg}$.

Contrast echocardiography was used at catheterisation in 8 patients (Fig. 3). After injection into the superior vena cava, the space between the posterior wall of the pulmonary artery and the midatrial echo was immediately opacified. This was followed within the same cardiac cycle by opacification of the pulmonary artery. At no time was there opacification of the atrial space posterior to the midatrial echo. These findings confirm that the midatrial echo does represent part of the atrial baffle and that the space anterior to it is part of the systemic venous atrium, the space posterior to it being part of the pulmonary venous atrium.

During systole, in the majority of cases, the midatrial echo moved forward to reach its maximum anterior displacement just after pulmonary valve closure; during diastole a similar posterior movement was seen parallel to the motion of the posterior pulmonary arterial wall suggesting that the baffle has little intrinsic movement because of changes in atrial volumes, but rather reflects the overall movement of the heart during the cardiac cycle. Measurement of the total excursion of the baffle gave values ranging from 2 to $11 \mathrm{~mm}$ (mean $6.5 \mathrm{~mm}$ ) which were similar to the values for pulmonary arterial wall excursion ( 2.5 to $13 \mathrm{~mm}$, mean $6.5 \mathrm{~mm}$ ). Additionally, in those patients in this study with atrial ectopic rhythms the movement of the baffle was indistinguishable from patients in sinus rhythm.

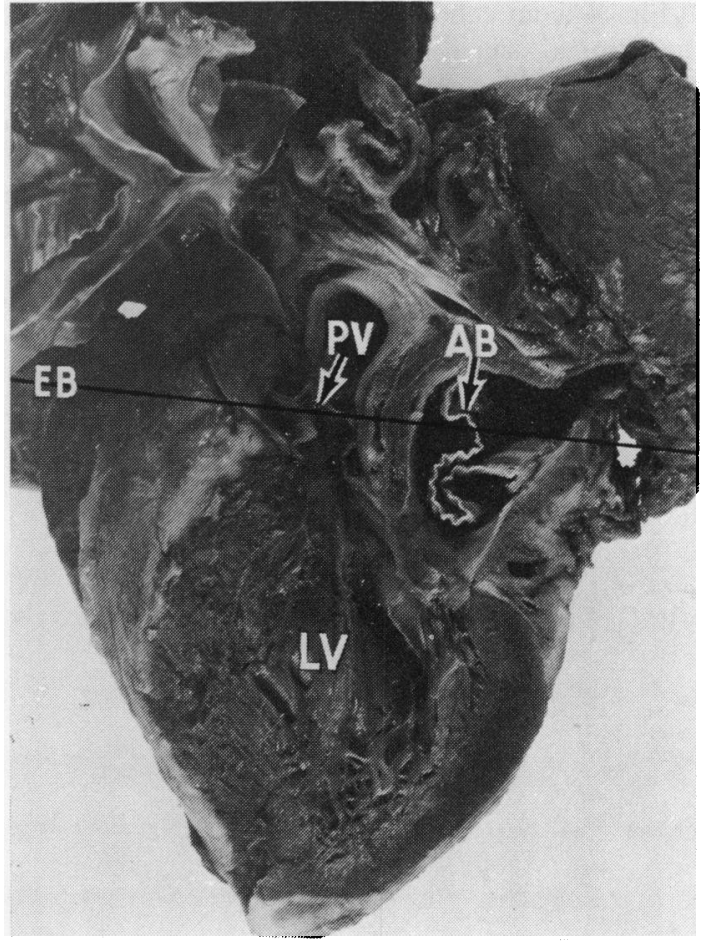

Fig. 1 A necropsy specimen of transposition of the great arteries after Mustard's operation, cut in the plane of the echocardiograph sweep. The course of the echo beam (EB) is shown by the line as it transects the pulmonary valie $(P V)$, and the interatrial baffle $(A B)$. The orientation of the heart within the chest means that in life the direction of the echo beam is usually slightly upwards. $L V$, left rentricle.

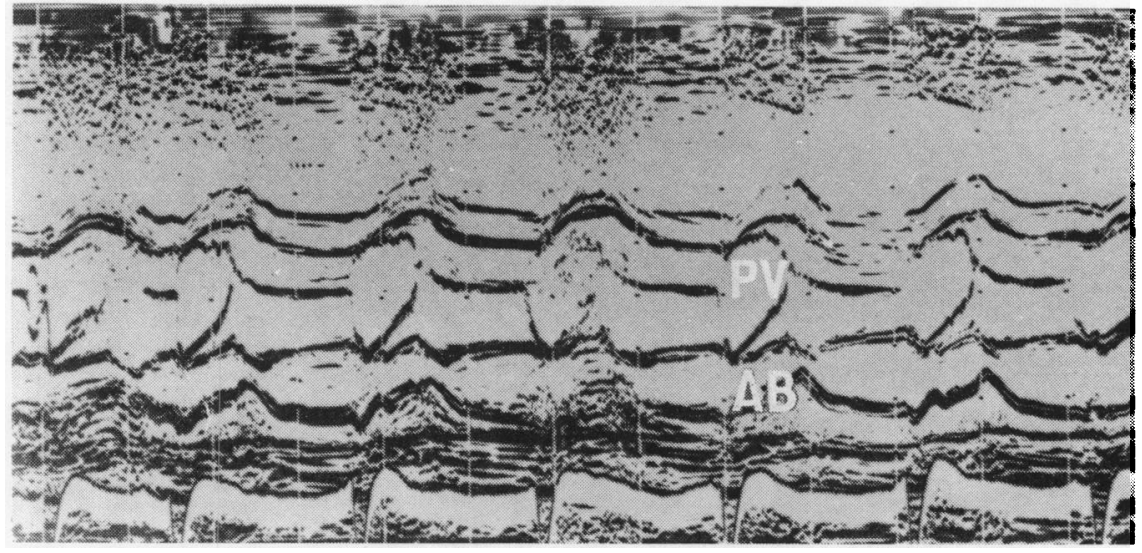

Fig. 2 An echocardiogram after Mustard's operation for transposition of the great arteries showing echoes from the pulmonary valve (PV) and the midatrial echoes originating from the interatrial baffle (AB). 
Fig. 4 is an echocardiogram from a patient with the clinical signs of severe superior vena caval obstruction. Multiple poorly moving echoes originating from the baffle filled the original left atrial cavity. Severe superior vena caval channel obstruction was shown on catheterisation and at reoperation the pericardial patch was thickened, constricted, and covered with deposits of fibrin and clot.

Because of changing surgical techniques 12 of the 30 patients had baffles constructed of synthetic material ('dacron' or 'teflon') and the remainder were of pericardium. There was no obvious difference echocardiographically between these two groups. The interval between the operation and the echocardiographic study varied from 7 weeks to 8 years, but there were no obvious differences in the echocardiographic appearances of the baffle which could be related to the length of the interval.

\section{Conclusions}

A mid-atrial echo can be visualised after the Mustard operation, and contrast echocardiography showed that this echo arose from the interatrial baffle. In the majority of cases the baffle echo is thin and moves parallel to the posterior wall of the pul-
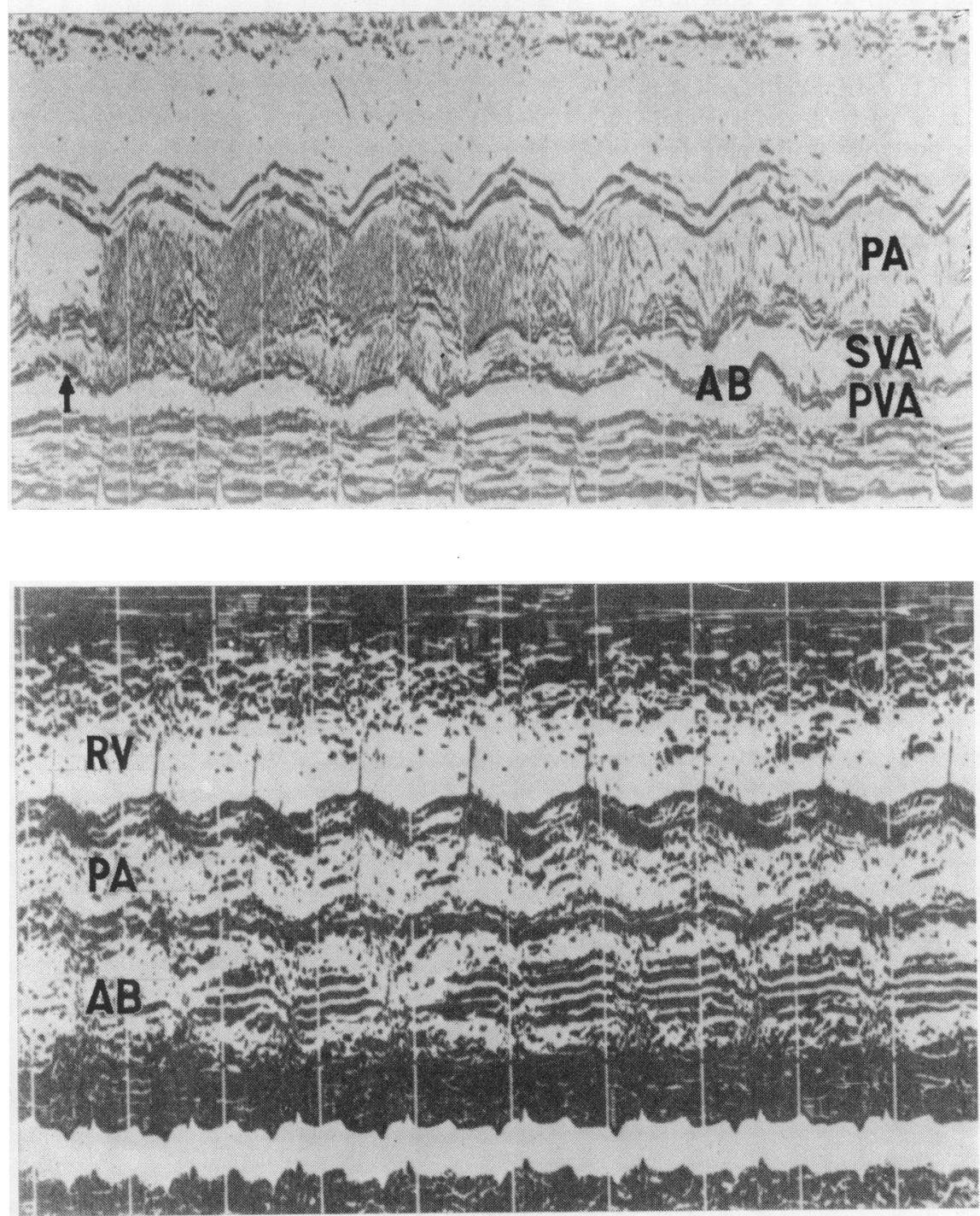

Fig. 3 A contrast echocardiogram with injection of 5 per cent dextrose into the superior vena cava. The appearance of contrast echoes in the space between the atrial baffle $(A B)$ and the pulmonary artery ( $P A)$ is shown by the arrow. This shows that the midatrial echo originates from the interatrial baffle, with the systemic venous atrium ( $S V A$ ) anterior to it and the pulmonary venous atrium (PVA) posterior.

Fig. $4 A n$ echocardiogram from a patient with severe superior vena caval channel obstruction showing multiple echoes originating from the atrial baffle ( $A B)$. $R V$, right ventricle; $P A$, pulmonary artery. 
monary artery. Thickening and limited motion of the baffle echo or multiple baffle echoes suggest that caval channel obstruction may be present. In only one case was there a false positive, but there were 3 patients with caval channel obstruction in whom the echo gave false negative information, the baffle echo looking normal.

Abnormal baffle echoes can provide useful corroboration of the clinical diagnosis of superior caval channel obstruction. The ease and regularity with which the baffle echoes can be shown make echocardiography a useful tool for the study of the time course of development of caval channel obstruction after Mustard's operation.

This study was supported in part by a grant from the Newcastle University Hospitals Scientific and Research Committee.

\section{References}

Gramiak, R., Shah, P. M., and Kramer, D. H. (1969). Ultrasound cardiography. Contrast studies in anatomy and function. Radiology, 92, 939-948.
Mustard, W. T. (1964). Successful two stage correction of transposition of the great vessels. Surgery, 55, 469-472.

Nanda, N. C., Stewart, S., Gramiak, R., and Manning, J. A. (1975). Echocardiography of the intra-atrial baffle in dextrotransposition of the great vessels. Circulation, 51, 11301135.

Seward, T. B., Tajik, A. J., Spangler, J. G., and Ritter, D. G. (1975). Echocardiographic contrast studies: initial experience. Mayo Clinic Proceedings, 50, 163-192.

Stark, J., Tynan, M. J., Ashcraft, K. W., Aberdeen, E., and Waterston, D. J. (1972). Obstruction of pulmonary veins and superior vena cava after the Mustard operation for transposition of the great arteries. Circulation, 45-46, Suppl. I, I-116-120.

Valdes-Cruz, L. M., Pieroni, D. R., Roland, J. M., and Varghese, P. J. (1975). Echocardiographic detection of right to left shunts by peripheral vein injections. Circulation, 52, Suppl. II, 474.

Requests for reprints to Dr. Stewart Hunter, Department of Cardiology, Newcastle General Hospital, Westgate Road, Newcastle upon Tyne NE4 6BE. 